\title{
DESAFIOS NA FORMAÇÃO DO PROFESSOR DE INGLÊS: DISCURSO, CONTEXTO SÓÇIO-HISTÓRICO, PRÁTICA E REFLEXÃO
}

\author{
Isabel Cristina Rangel MORAES BEZERRA \\ (Universidade do Estado do Rio de Janeiro) \\ icmoraes@uol.com.br
}

Resumo: Neste artigo, abordo o processo formativo do professor de inglês apontando alguns desafios que, embora não sejam novos, ainda precisam ser considerados se pensarmos nesse profissional como intelectual (GIROUX, 2007) que pode colaborar para o design do futuro social (COPE e KALANTZIS, 2005) nesse momento em que a certeza é a mudança. Após discutir a centralidade do discurso e do letramento para a formação do professor de línguas, apresento a Prática Exploratória (ALLWRIGHT, 2001; MILLER, 2013) e sua contribuição para o processo formativo. Finalmente, analiso uma experiência de produção de material para ensino de compreensão escrita em língua inglesa vivida por um licenciando.

Palavras-chave: Formação do professor de inglês. Discurso. Ensinoaprendizagem. Letramento.

\section{CHALLENGES IN THE EDUCATION OF ENGLISH TEACHERS: DISCOURSE, SOCIOHISTORICAL CONTEXT, PRACTICE AND REFLECTION}

\begin{abstract}
In this paper I discuss some challenges regarding the initial education of English teachers. Although they are not new, I think it is worth revisiting them, bearing in mind Giroux's (2007) claim for teachers to be conceived as intellectuals who can help design the social future (COPE e KALANTZIS, 2005) in a moment when the only certainty is change. After discussing the centrality of discourse and literacy regarding language teacher education, I present Exploratory Practice (ALLWRIGHT, 2001; MILLER, 2013) and some of its tenets and reflect on the possible contributions it can make. Eventually, I analyze the experience of material production for the development of reading comprehension skills in English lived by one pre-service teacher.
\end{abstract}

Keywords: English teacher education. Discourse. Teaching-learning. Literacy. 


\section{Introdução}

Para discutir a formação, a prática do professor de línguas, bem como o papel do formador é preciso, de início, configurar o pano de fundo em que se inscrevem práticas formativas e como elas estabelecem algum diálogo com as questões que se destacam, uma vez que nem a formação nem a prática docente se estabelecem em um vácuo social. As práticas formativas se inscrevem em contextos socioculturais concretos em que a pluralidade de se viver a experiência humana é uma dado, via de regra, não reconhecido pelas instituições escolares, em práticas discursivas que, muitas vezes encaminham para o apagamento das vozes de alunos e de professores.

Neste artigo ${ }^{1}$, trago alguma reflexão sobre desafios na formação do professor de línguas a partir de alguns macros campos que apresento adiante. Embora haja muitas reflexões em Linguística Aplicada sobre a formação desse professor (ROMERO, 2011; PESSOA, 2011; BARCELOS, 2010; LIBERALI, MAGALHÃES, ROMERO, 2003; CRISTOVÃO, 2002; ABRAHÃO; 2002), a importância da constante revisitação a essa questão dá-se exatamente se for considerado o papel do discurso no mundo social para a vivência de diversas experiências de ser humano e de ser cidadão. Na área de formação do docente de línguas, mapear desafios é tarefa fácil - mesmo porque muitos não são tão novos assim. Difícil, contudo, é abarcar todos os que se apresentam para reflexão dos professores formadores, dos licenciandos ou de outros atores envolvidos no processo formativo. Assim, trato de alguns desafios com os quais tenho me deparado em minha prática de professora formadora, os quais têm sido objeto de reflexão constante para mim, considerando o cenário sóciohistórico que vivenciamos. Nesse contexto, a Prática Exploratória (PE) tem sua contribuição a dar por ser uma abordagem para o ensino-aprendizagem, para a reflexão e a pesquisa dos praticantes - professor formador e professor préserviço, no presente estudo - encorajando a construção de um olhar percuciente à vida em sala de aula e fora dela na qual circulam discursos e ideologias, dimensionando o fazer docente da mesma forma que o estar em

\footnotetext{
${ }^{1}$ Agradeço imensamente às professoras Inés Kayon de Miller (PUC-Rio) e Evellyn Juliane da Rocha Brandão (Colégio Estadual Machado de Assis) pela leitura e comentários a esse artigo.
} 
sala de aula tanto para alunos quanto para professores. O fazer da PE abre espaço, portanto, para que esses atores sociais tragam suas questões significativas para suas vidas - de modo a entendê-las, entendendo-se. Ao ser encorajada pela PE a sempre refletir sobre o próprio contexto de atuação profissional, trago uma experiência construída com um bolsista que esteve sob minha supervisão em um projeto de iniciação à docência direcionado para a produção de material didático para o ensino de compreensão escrita em língua inglesa.

\section{Ponto de partida: a centralidade do discurso, a relevância do letramento.}

As questões que abordo inscrevem-se no escopo da Linguística Aplicada. Esta área tem, no Brasil, uma tradição de pesquisa e reflexões no que tange a formação do professor de línguas e, consequentemente, o ensino de línguas materna e estrangeira. Assim sendo, uma das questões centrais para essa temática diz respeito ao uso da linguagem nas práticas sociais dentro e fora de contextos escolares.

Moita Lopes (2006, p. 22), discutindo a prática de pesquisa em LA, afirma que

politizar 0 ato de pesquisar e pensar alternativas para a vida social são parte intrínseca dos novos modos de teorizar e fazer LA. Assim, a LA precisa de teorização que considera a centralidade das questões sociopolíticas e da linguagem na constituição da vida social e pessoal.

É essa indicação que orienta a discussão que trago. Da mesma forma, entendo que essa orientação possa ser tomada como norteadora do processo formativo do professor de línguas em geral e, na discussão em tela, do professor de inglês, exatamente porque vai dimensionar o objeto de ensino - a língua - e seu papel constitutivo no mundo social. Portanto, para pensar a formação do professor, escolho os seguintes macrocampos e seus desafios: discurso e letramento, configuração sócio-histórica, prática e reflexão docente.

Nessa perspectiva, proponho que o processo formativo do professor deva privilegiar o discurso, entendido enquanto elemento carreador de ideologias que criam realidades como efeito, crenças, posicionamentos de quem fala ao 
outro e de como posiciona este outro nas práticas discursivas (Fairclough, 1995). Assim, a prática de ensinar uma língua não pode fundamentar-se em um entendimento essencialista desse objeto, privilegiando o trabalho mecânico com a estrutura ou vocabulário. Trata-se de ensinar língua, conforme Halliday levantou há algum tempo, enquanto potencial de significados. Esses são concretizados a partir de escolhas que o usuário faz no sistema da língua. Tais escolhas são os índices que marcam os posicionamentos ideológicos, de crenças, etc. de quem a utiliza nas diversas práticas sociais nas quais nos engajamos em diversos gêneros discursivos que circulam socialmente.

Seguindo Goodwin e Duranti ([1992] 1997), o discurso é um complexo cultural de signos e de práticas que regulam a forma como vivemos socialmente. Segue-se que "o discurso [tanto] é constitutivo como é socialmente condicionado [...] O discurso é constitutivo tanto no sentido de que ele ajuda a sustentar e a reproduzir o status quo social como ele contribui para transformá-lo" (WODAK, 1997, p.173). Coadunando com esses autores, Jordão e Fogaça (2007, p. 87), discutindo o ensino de línguas estrangeiras (LE), lembram que

quando a língua é definida como discurso, o ensino de LEs se torna o ensino de novas formas de nos compreendermos e de percebermos o mundo. A língua como discurso implica o entendimento de nossas práticas de linguagem como práticas de (re)significarmos o mundo e o que acontece em nossa volta, a forma como percebemos a realidade.

Tendo em vista a presença fundante do discurso na construção das interrelações humanas, das identidades e do mundo social (MOITA LOPES, 2002), não há como não trazer para a reflexão um outro elemento, qual seja, o letramento. Para essa reflexão, mais especificamente, a contribuição de Cope e Kalantzis ([2000]2005) ao tratarem de múltiplos letramentos. Os autores localizam a proposta desse construto analisando a ordem cultural, institucional e global emergente. Os autores distinguem 'mero letramento', característico de uma prática pedagógica tradicional, de uma pedagogia de 'múltiplos letramentos'. Para eles, o primeiro estaria centrado apenas na língua, "normalmente em uma única forma de língua nacional, sendo concebida como um sistema estável baseado em regras" (COPE, KALANTZIS, 2005, p.5). Considerando o letramento do professor de inglês que, via de regra, inicia-se 
fora da universidade, o mero letramento parece ser aquele que ainda vige em muitas instituições de ensino superior. Perpassa essa pedagogia de letramento tradicional em língua inglesa a visão de um inglês monolítico, ou, por vezes, a dicotomia 'inglês britânico' por um lado, e 'inglês americano' por outro. Não se cogita no inglês australiano, nem no neozelandês. Não se consideram as diversas formas de usar o idioma nesses países no cotidiano das práticas sociais e discursivas em que as pessoas se engajam. Muito menos se considera o uso feito da língua inglesa como língua internacional por falantes de diversos países.

Em decorrência, essa prática formativa no âmbito do entendimento monolítico da língua faz com que seja reforçada a crença de muitos licenciandos de que aprender a usar um idioma envolve apenas o conhecimento de regras gramaticais e de seu vocabulário. Aspectos sociais, culturais, ideológicas, por exemplo, não são considerados. As implicações desse modelo para as práticas docentes em formação refletem-se possivelmente na aula cujo conteúdo central é um dado elemento gramatical e as regras para sua aplicação em exercícios estruturais, sendo a frase a unidade de ensino. Os textos são usados para atividades vinculadas a regras gramaticais ou sobre vocabulário, sem a preocupação com contexto de produção-recepção, com o design do texto, com a seleção lexical, etc.

Os 'múltiplos letramentos', por outro lado, apontam para uma pedagogia que "foca em modos de representação mais amplos que a língua apenas. Estes diferem de acordo com a cultura e contexto e têm efeitos cognitivos, culturais e sociais específicos" (COPE e KALANTZIS, [2000]2005, p.5). Há situações em que o modo de representação visual é "mais poderoso e mais relacionado à linguagem do que o mero letramento poderia permitir" (ibid.). Na verdade, os autores enfatizam que há um aumento e multiplicidade nas formas de construir significados na contemporaneidade. Elas estão relacionadas ao visual, ao gestual, ao áudio, ao arquitetônico, dentre outros e são importantes nas mídias de massa, nas multimídias e nas hipermídias eletrônicas. Isso significa aprender a ler não a apenas o que está escrito, mas imagens, espaços físicos, etc. Essa pedagogia dos múltiplos letramentos, portanto, vai além do texto, apontando que, na contemporaneidade, muito mais do que antes, é 
preciso ir além da palavra escrita, ou melhor, é preciso entender a articulação de variadas formas de construir significado para agir no mundo social.

As implicações desse modelo para as práticas docentes em formação não significam a eliminação de estudos de elementos linguísticos pertinentes ao texto, por certo, mas devem privilegiar o discurso, com foco em elementos linguístico-discursivos, semióticos, etc., usados para a construção de textos orais e escritos de diversos gêneros a fim de conduzir um olhar crítico às diversas formas de construir significados sobre o mundo social e as práticas que nele se configuram, sobre o outro e sobre. Nesse sentido, devem ser consideradas não apenas formas canônicas de textos, mas formas marginais; não apenas a língua padrão, mas todas as formas de expressão na língua que remetam às questões humanas, inclusive às mais cotidianas da vida social.

Se o significado é cada vez mais construído de maneira multimodal, em que os modos de escrita estão visceralmente vinculados, por exemplo, aos modos visual, de áudio e espacial de significar. Todos são reelaborados a cada dia pelos usos que fazemos da língua e pela utilização de novas tecnologias disponíveis. Assim, não há como educar o professor de línguas para ater-se apenas a um único letramento. Certamente não é o ensino da língua estrangeira ou materna - para a comunicação, mas para entender o que se faz em termos de ação social pelo discurso (ou discursos) e por aqueles modos de significar no que tange ao exercício de poder; à inclusão/exclusão de pessoas no acesso a bens culturais e ao mercado de trabalho; ao respeito às diferenças; às formas de se ver as diferenças nas relações interpessoais, dentre muitos outros pontos.

\section{O contexto sócio-histórico e a prática docente.}

É perceptível o quanto as discussões teóricas sobre uso da língua e formação docente abordada na seção precedente estão profundamente vinculadas à configuração sócio-histórica que vivemos. A formação para o trabalho e a formação do professor de línguas, em especial, não podem ser entendidas como algo que acontece em um vácuo social (MOITA LOPES, 2003), como se as práticas sociais desenvolvidas nos espaços formativos 
(MORAES BEZERRA, 2011) não incluíssem ou não estivessem plenas de questões que tenham sua origem na luta de minorias, nas representações sobre como meninos/homens e meninas/mulheres devem ser, estar e agir discursivamente no contexto escolar, ou como são e como devem agir professores de certas disciplinas, ou ainda sobre qual deva ser o conteúdo privilegiado em sala de aula.

Definitivamente a sala de aula não é uma ilha. Consequentemente também não o são as instituições formadoras. O que acontece globalmente reverbera no espaço local. Quanto a isso, Giddens (2003, p.15) aponta que a "globalização está reestruturando o modo como vivemos e de uma maneira muito profunda. [...]. Além disso, a globalização influencia a vida cotidiana tanto quanto eventos que ocorrem numa escala global". Nesse cenário, aponta ainda o autor, que o mundo, ao invés de estar sob nosso comando, mais parece um mundo em descontrole.

Santos ([2000]2011) assevera que a globalização representa o auge do processo de internacionalização do mundo capitalista, pois há um conjunto de técnicas que envolve o planeta, fazendo sentir sua presença de imediato. A técnica da informação - com a cibernética e redes de computadores - é central neste cenário por permitir a comunicação entre diversas técnicas como as da economia e a da produção. Ela tem "papel determinante sobre o uso do tempo, permitindo em todos os lugares, a convergência dos momentos, assegurando a simultaneidade das ações e, por conseguinte, acelerando o processo histórico" (SANTOS, [2000]2011, p.25). Giddens (2003, p. 14) coloca ainda que "algumas das influências que, supunha-se antes, iriam tornar a vida mais segura e previsível para nós, entre elas o progresso da ciência e da tecnologia, tiveram o efeito totalmente oposto".

A globalização tanto divide quanto une, da mesma forma que divide enquanto une, conforme aponta Bauman (1999, p.8). Entendendo que as certezas das estruturas sociais e instituições características da fase sólida da sociedade deram lugar a uma fase líquida, o autor (2007) problematiza o mercado de trabalho e as relações que as pessoas estabelecem em seus contextos de atuação profissional. Segundo o autor, 
A exposição dos indivíduos aos caprichos dos mercados de mão-de-obra e de mercadorias inspira e promove a divisão e não a unidade. Incentiva as atitudes competitivas, ao mesmo tempo em que rebaixa a colaboração e o trabalho em equipe à condição de estratagemas temporários que precisam ser suspensos ou concluídos no momento em que se esgotarem seus benefícios. (Bauman, 2007, p.9)

Neste cenário, vale ainda apontar que, segundo Gee (2000), há um novo capitalismo emergente. Ele está mudando o formato de negócios e da escola, estabelecendo uma nova lógica. Contribuindo para a reflexão sobre a globalização, Santos ([2000]2011, p.39) acentua o papel do discurso:

O fato de que, no mundo de hoje, o discurso antecede quase obrigatoriamente uma parte substancial das ações humanas - sejam elas a técnica, a produção, o consumo, o poder - explica o porquê da presença generalizada do ideológico em todos esses pontos. Não é de estranhar, pois, que a realidade e ideologia se confundam na apreciação do homem comum, sobretudo porque a ideologia se insere nos objetos e se apresenta como coisa.

No entanto, defendendo a construção de outra globalização menos perversa através do próprio discurso, o autor (ibid., p.74) afirma:

Por aí se vê que a questão capital é o entendimento do nosso tempo, sem o qual seria impossível construir o discurso da liberação. Este, desde que seja simples e veraz, poderá ser a base intelectual da política. E isso é central no mundo de hoje, um mundo no qual nada de importante se faz sem discurso.

No cenário de inseguranças, Beck (1997) traz a ideia da sociedade de risco, coadunando com Giddens (2003), apresentado acima, no sentido de que "as instituições da sociedade tornam-se os produtores e legitimadores das ameaças que não conseguem controlar" (BECK, 1997, p.15,16). Essa sociedade de risco "torna-se reflexiva (no sentido mais estrito da palavra), o que significa dizer que ela se torna um tema e um problema para ela própria" (ibid., p.19). Acontece que tal reflexividade só é possível, como esclarece Moita Lopes (2003, p.34), "pelo discurso que a vai moldando continuamente como também a nós mesmos".

Certamente, o formador de professores de línguas não pode ignorar tais questões. Deve estar atento a elas. Neste sentido, Moita Lopes (2003) chama atenção para o fato de que, em sala de aula, o professor precisar levar a sócio- 
história em consideração a fim de situar sua prática uma vez que "uma visão de educação assentada em um vácuo social em que a sócio-história não tem lugar na sala de aula tem sido amplamente criticada" (MOITA LOPES, 2003, p. 32). Embora o autor teça tal consideração em relação ao professor e aos alunos dos ensinos fundamental e médio, ela pode ser estendida ao formador de professores de inglês e aos licenciandos, uma vez que, na nova configuração mundial, o professor de inglês tem uma posição importante porque

os discursos que circulam internacionalmente, em virtude do predomínio do capital norte-americano no chamado mundo globalizado em todos os campos da vida social, isto é, do comércio até a pesquisa universitária, passando pelas redes de transmissão de notícias, são primordialmente construídos em inglês. (MOITA LOPES, 2003, p. 40)

Tal assertiva deve levar professores formadores, em especial os que ministram aulas de língua inglesa e de disciplinas que abordam propostas metodológicas para o seu ensino, a perquirir se as bases nas quais fundamentam essas disciplinas atendem aos desafios dessa sócio-história. Giroux e Simon assinalam (2002, p. 95,96) que, "nas escolas, os significados são produzidos pela construção de formas de poder, experiências e identidades que precisam ser analisadas em seu sentido mais amplo". Isso nos leva a pensar sobre currículos e sobre os conteúdos selecionados para o efetivo trabalho em sala de aula, tanto no processo de formação de professores de inglês quanto no exercício da docência na educação básica.

Assim, sem reduzir o processo formativo do professor de inglês a uma 'receita', dado que as questões envolvidas são muito complexas, uma possibilidade de encaminhar essa formação no que concerne à língua seria delinear não apenas a prática do formador, mas também a do professor em formação, tomado por base o entendimento de língua como discurso e a proposta dos multiletramentos. Dessa forma, tanto a atuação do formador quanto a do licenciando, através do desenvolvimento de sua prática posterior em sala de aula, podem colaborar para a construção do mundo social em outras bases, já que "aprender uma língua é aprender a se envolver nos embates discursivos que os discursos a que somos expostos em tal língua 
possibilitam [...] para construir outros mundos sociais melhores ou outros significados sobre quem somos" (MOITA LOPES, 2003, p. 45).

\section{Prática docente e reflexão}

Outro elemento desafiador em relação à prática docente na formação do professor diz respeito à articulação da mesma a uma prática reflexiva. Isso não significa que professores não pensem sobre seu fazer, mas caberia estabelecer uma prática reflexiva que fosse sustentável e contínua, priorizando a qualidade de vida, envolvendo todos os participantes e gerando entendimentos que contribuíssem para o desenvolvimento de todos (Moraes Bezerra, em andamento). Matos ([1998]2000) apontou a valorização que a reflexão estava assumindo na formação e no desenvolvimento profissionais na década de noventa. Contudo, o autor não a advogava como "fórmula mágica para responder aos desafios educacionais do momento", em especial se considerarmos a sócio-história em que as práticas docentes se inscrevem.

Entendo que esse desejo de reflexividade por parte do professor está atrelado às condições da modernidade reflexiva problematizada por Beck (1997), a qual está continuamente moldando - ou reconstruindo - a sociedade e cada um através das práticas discursivas, do modos de produzir significação como colocado pela perspectiva dos multiletramentos. No contexto escolar, a prática reflexiva pode levar os envolvidos a construir práticas docentes e identidades dos envolvidos em outras bases mais alinhadas à perspectiva da ética, do respeito, do coleguismo, do desenvolvimento de todos.

Tendo tais questões em mente e embora reconheça a relevância de várias propostas para encaminhamento da reflexão docente na área da formação do professor de inglês, acredito que a Prática Exploratória tenha algo a contribuir. Ela é uma abordagem reflexiva articulada ao ensinoaprendizagem de línguas e tem contribuído para a construção de inteligibilidade sobre o contexto escolar e sobre formação de professores (MILLER, 2013, 2012; RODRIGUES, 2014; VILLELA, 2012). Em sua proposta, professores e alunos desenvolvem seus entendimentos acerca de aspectos que os intriguem - sejam eles relativos ao uso da língua, ao relacionamento 
interpessoal, à vida dentro e fora da escola, por exemplo - enquanto estão engajados nas tarefas que thes são peculiares. Ou seja, o trabalho para entender é feito através de procedimentos pedagógicos já familiares, tais como atividades orais em pares ou grupos, produção de textos (cartas, bilhetes, capas de revistas, relatórios, etc.), dentre muitas outras. Quando utilizadas para fins de envolver todos no processo reflexivo, os proponentes da PE chamam-nas de Atividades Pedagógicas com Potencial Exploratório (APPE), pois sofrem algumas modificações para provocar o pensar sobre as questões de interesse de algum praticante em especial ou do grupo. Elas dependerão dos puzzles ou questões sobre as quais se deseja investigar e, como Miller (2013) apontou, da criatividade investigativa do grupo envolvido.

A atitude reflexiva trazida pela abordagem da PE não deve ser entendida como algo imposto ao professor (ALLWRIGHT, 2001a, 2001b), mas sim como algo inerente às competências que o professor de línguas deve desenvolver para se constituir enquanto sujeito do seu fazer e profissional em constante interlocução com seus colegas e alunos. A PE prioriza uma atitude antitecnicista do fazer do professor, posto que o domínio das técnicas do fazer pedagógico em si não garantem a aprendizagem nem a qualidade da vida que se vive na sala de aula. $O$ viés filosófico da PE encoraja os praticantes a entenderem as questões que surgem antes de trazer qualquer alternativa que implique tentativa de solução de problemas, pois, como já foi abordado, questões da vida - em seu contínuo dentro e fora de sala de aula - não são passíveis de serem facilmente solucionadas. Por isso, priorizar a qualidade de vida em sala de aula (e em outros espaços de aprendizagem na escola/universidade) e o entendimento sobre ela é crucial. Gieve e Miller (2006) argumentam que, ao voltarem-se para a qualidade de vida, os praticantes interessam-se 'pelo que está acontecendo' em sala de aula (ou em outros espaços de aprendizagem na escola/universidade) nos termos goffmanianos (Goffman, 1974). Tal interesse leva os praticantes exploratórios a focar a peculiaridade e a complexidade envolvida na compreensão de 'qualidade'.

Gieve e Miller (2006, p. 20) problematizam que a própria noção de 'qualidade' envolve múltiplas interpretações a partir de enquadres de 
expectativas sobre o que constitui qualidade boa ou ruim na experiência em sala de aula. Considerando que tais enquadres são sócio-histórica e discursivamente situados e construídos no plano interpessoal, os entendimentos sobre questões semelhantes podem variar de um grupo de praticantes para outros em suas diferentes salas de aulas e mesmo para o olhar de um observador externo. Da mesma forma, o entendimento que do pode ser considerado 'boa qualidade de vida' do ponto de vista tecnicista para alguém que coloque nas técnicas a relevância do trabalho do professor, pode ser encarado como ‘qualidade de vida ruim' pelo praticante exploratório que prioriza o humano.

Nesse movimento de debruçarem-se sobre suas questões na 'ação para entender', os praticantes acabam por renegociar e recriar a vida nesse contexto, operando no viés da transformação. A PE encoraja a agência dos praticantes envolvidos e do professor, em particular, como intelectual transformador (GIROUX, 1997). Todos são lídimos produtores de conhecimentos com relevância local. Sobre essa questão em particular, Gieve e Miller (2006, p.41) afirmam que

Professores e alunos, ao buscarem coletivamente construir entendimentos, articulando-os uns aos outros, estão desenvolvendo uma rica consciência sobre a sala de aula através da qual a natureza da experiência em sala de aula tornase qualitativamente melhor. [...] Sugerimos que há um efeito empoderador para professores e alunos ao desenvolverem [seus entendimentos] o que pode ser uma ação não apenas contínua, mas igualmente transferida para outras instâncias de suas vidas.

A abordagem reflexivo-pedagógica da PE, portanto, encaminha-se no sentido da construção da agência e da autonomia dos praticantes, em especial dos alunos, posto que, segundo Allwright e Hanks (2009, p. 7), os aprendizes são indivíduos únicos que aprendem melhor de seu próprio jeito. Ao mesmo tempo são seres sociais que aprendem e se desenvolvem melhor em um ambiente de suporte mútuo. Eles levam o aprendizado a sério, sendo capazes de tomar decisões autonomamente. Por fim, são capazes de se desenvolver como praticantes de aprendizagem. Essas proposições podem fazer parte da configuração de um projeto de formação do professor para atuar nas escolas reconfigurando ou, como Moita Lopes apontou, reconstruindo discursivamente 
as identidades de professores e alunos, desconstruindo o 'desejo do controle' pelo da 'participação responsável' na construção não apenas de aulas mais significativas, mas de outras relações interpessoais e de outras relações com o saber.

A abordagem da PE, portanto, coaduna-se com as questões levantadas nas seções precedentes. Ela tem grande potencial transformador e pode se utilizada na universidade como uma abordagem formativo-reflexiva agregada à prática do formador e do licenciando. Assim, formadores de professores podem construir um espaço reflexivo apoiado na abordagem da PE, encorajando os licenciandos a proporem puzzles, ou questões a serem investigadas, acerca de qualquer perspectiva da vida em sala de aula, mormente sobre o próprio processo formativo e a prática inicial.

\section{Contextualizando um percurso formativo e fazendo sentido da experiência}

A universidade onde trabalho possui, desde 1999, um programa interno de bolsas para algumas atividades discentes, objetivando não apenas que os alunos participem em atividades acadêmicas, mas também sua atuação se desenvolva em projetos que tenham planos de trabalho com atividades definidas. Uma modalidade de bolsas oferecida está vinculada a projetos de iniciação à docência (ID). Tais projetos devem trabalhar com metodologias que possam contribuir para a educação básica e o ensino médio.

Para tentar problematizar a formação do professor de inglês face aos desafios que tentei delinear, apresento a experiência vivida no projeto de ID $^{2}$ que coordenei com foco na produção de material didático para o ensino de compreensão escrita em língua inglesa. A proposta do projeto de ID pode ser observada abaixo. Nela era advogada uma formação que buscasse articular os aspectos teórico-metodológicos à prática docente inicial de maneira reflexiva.

\footnotetext{
${ }^{2}$ Este projeto foi coordenado pela professora Renata L. de Almeida Rodrigues e por mim (UERJ). Ele esteve ativo de 2007 a 2013.
} 
Para isso, é preciso que, durante sua formação, além das questões teóricas da área, haja espaço para que o licenciando possa planejar, implementar e refletir sobre o fazer docente, estabelecendo um diálogo entre teoria e prática. $O$ presente projeto insere-se exatamente neste espaço por oferecer ao licenciando de língua inglesa não apenas a oportunidade de desenvolver sua competência de uso social da língua inglesa, de construir conhecimentos sobre o ensino de leitura, planejar e implementar atividades visando o desenvolvimento dessa habilidade linguística, mas, principalmente, de entender suas ações e decisões durante o processo ao refletir sobre sua prática pedagógica. Com isso, o licenciando poderá construir uma perspectiva da dimensão social da ação docente, especialmente da ação do professor de língua estrangeira no contexto brasileiro. (Projeto "Aulas e material de leitura: uma perspectiva da formação docente em língua inglesa")

A Prática Exploratória era o eixo condutor de toda a atividade de orientação, reflexão sobre a prática inicial e produção do material didático. Durante os encontros de orientação do projeto que aconteciam semanalmente, discutíamos textos teóricos diversos para embasar a produção do material. Discutíamos, em especial, os PCN-LE por tratar-se de um documento que apresenta base teórica e discussão que coaduna com as questões tratadas nas seções anteriores. Além disso, traz orientações didáticas para a construção de aulas de leitura. Os licenciandos eram encorajados a selecionar textos para a produção de unidades para o ensino de leitura que permitissem o trabalho com temáticas relevantes para o aprendiz, alinhados aos temas transversais e à contemporaneidade - como o mundo atravessado pelas técnicas da informação e da propaganda, o mundo adolescente e o consumo, os conflitos humanos, alimentação e saúde, posição da mulher em diversos textos, dentre inúmeros outros.

\section{1- O bolsista, uma atividade de leitura e um relatório}

À luz das questões apresentadas nas seções anteriores, escolhi, como foco da reflexão construída através do presente texto, analisar dois momentos da atuação de Roger, um bolsista que participou do projeto de ID. Roger ${ }^{3}$ participou de um processo seletivo a fim de conseguir a bolsa para o projeto e permaneceu em atividade por dois anos. Durante todo esse tempo produziu material didático em parceria com um colega e sozinho. Sempre buscava

\footnotetext{
${ }^{3}$ Esse é um nome fictício.
} 
trazer seus porquês para a discussão e era encorajado a pensar mais profundamente sobre os mesmos. Assim, alinhado à abordagem da PE, tais porquês geraram, inclusive, puzzles, que encaminharam a reflexão enquanto esteve conosco no projeto. Alguns desses porquês e entendimentos apontando a qualidade de vida construída em nossas interações foram apresentados por Roger em um evento anual da Prática Exploratória na PUC-Rio, onde está estabelecido o Grupo de Prática Exploratória no Brasil.

Para encaminhar o processo reflexivo pelo viés da $P E$, além da reflexão constante ao material em produção, Roger foi envolvido em uma busca por entendimentos sobre sua formação. As discussões de textos e do material durante as reuniões de orientação já provocavam a reflexão e a construção de entendimentos. O relatório a ser produzido para a instituição como parte de suas tarefas de bolsista foi usado igualmente como espaço discursivo reflexivo. Dessa forma, a redação do texto produzia o efeito de pensar o processo formativo, a qualidade da vida imbricada no mesmo.

Dentre as unidades de leitura desenvolvida por Roger ao longo de sua trajetória, trago para um pensar mais cuidadoso, uma vez que o presente trabalho também é para mim uma oportunidade de aprendizagem através da reflexão, uma atividade produzida a partir de um texto que chamou sua atenção na internet. Seria uma oportunidade de refletir coletivamente sobre uma questão que afetava a qualidade de vida das pessoas naquele momento, segundo ele. O design do boneco de traços tão simples, ao mesmo tempo tão repleto de significado, fez com que Roger percebesse o potencial do mesmo para a discussão das relações humanas em tempo de redes sociais. Assim, ao perceber o valor do aspecto multimodal para a construção de significados, Roger, de certa forma, se alinhava à perspectiva dos múltiplos letramentos.

4.1.1 A pré-leitura e o texto:

Pré-leitura:

[a] Você costuma usar a internet para se comunicar com as pessoas?

[b] Você já conheceu alguém pela internet?0 


\section{Net Friends}

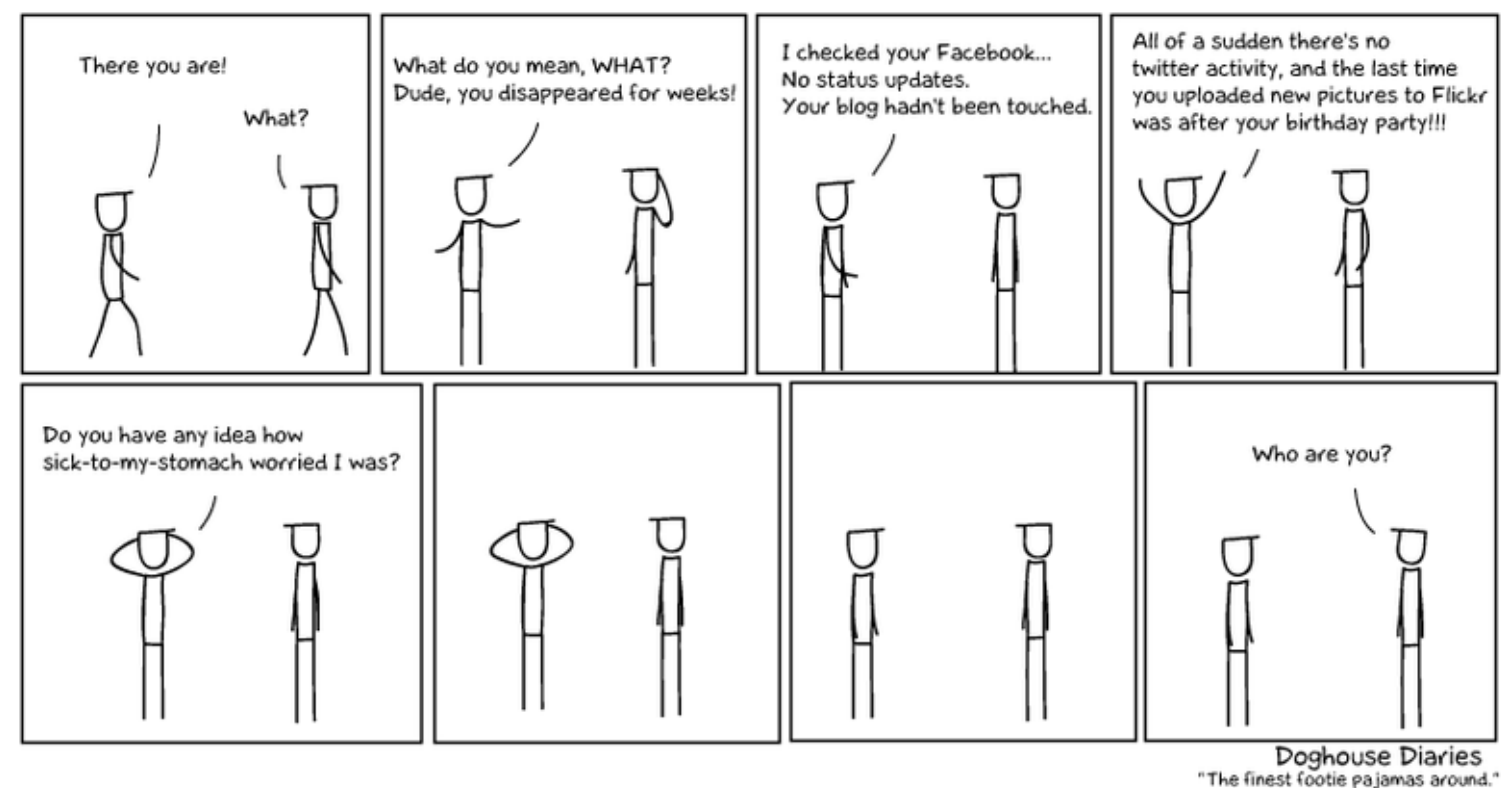

Retirado de http://www.funnyjunk.com e acessado em 11 de maio de 2010

As perguntas da pré-leitura propostas por Roger ativam o conhecimento de mundo (BRASIL, 1998) dos alunos sobre o tema a ser tratado, embora não levem o aluno a buscar no texto alguma pista sobre a relação entre as perguntas e a temática abordada. É uma forma de preparar o terreno para a abordagem mais detalhada ao texto. Ressalto como o texto selecionado coadunava-se com a visão do projeto e nosso objetivo de trazer para a sala de aula temas significativos e relevantes para o mundo social.

\subsubsection{As atividades propostas aos alunos - I}

1-Que tipo de texto é esse? Como você chegou a essa conclusão?

2- Qual é o tom desse texto?

$$
\begin{aligned}
& \text { ( ) cômico /sarcástico } \\
& \text { ( ) informativo / impositivo }
\end{aligned}
$$

Explique como você chegou a essa conclusão?

3-Por que você acha que a palavra what no segundo quadrinho está em caixa alta?

A atividade 1 traz uma pergunta que aciona conhecimento sobre organização textual (BRASIL, 1998). Ao encorajar o aprendiz a fazer um 
esforço de metacognição no sentido de mapear elementos nos níveis visual e linguístico discursivo no texto que ajudam a identificar o gênero, Roger busca o uso de metalinguagem pelo aprendiz, ao mesmo tempo opera no sentido de desconstruir uma perspectiva da aula de inglês focada da sentença e na manipulação de frases. Seu foco é uma unidade maior de ensino: o texto.

A segunda atividade convida o aprendiz a tentar identificar o 'tom' do texto. Ela é interessante porque existe a possibilidade de o aprendiz indicar outra resposta além das alternativas apresentadas. Novamente a tarefa envolve metacognição uma vez que o aprendiz precisa explicitar o que foi levado em consideração para oferecer aquela resposta. Em uma das reuniões em que discutimos essa atividade, sugeri a Roger que a segunda atividade viesse em um momento posterior no encadeamento das tarefas para que o aluno pudesse reunir mais elementos que o ajudassem a responder. Roger, contudo, explicou o porquê de haver colocado a tarefa naquele momento, argumentando pela manutenção da mesma. Minha colega e eu respeitamos sua decisão, afinal, era nosso desejo contribuir para a construção da autonomia dos bolsistas no tocante às suas decisões.

A terceira atividade exige um conhecimento de elementos semióticos agregados ao texto por parte do aprendiz. Essa é uma questão interessante porque Roger não propõe uma atividade para resgatar o significado da palavra what, mas, em termos de negociação de significado, o aprendiz precisaria apontar que contribuição daria para o entendimento do texto o fato de a interjeição estar em caixa alta. Essa forma de tratar o texto para o ensino, focando a semiose, já dimensiona uma perspectiva de trabalho docente considerando os multiletramentos, como abordado anteriormente.

\subsubsection{As atividades propostas aos alunos - II}

4- No segundo quadrinho, podemos perceber que uma das personagens se dirige a outra através da palavra dude. Observe os exemplos abaixo:

[a] Dois amigos estão conversando no pátio da escola. Um deles é conhecido por ser super engraçado, e simplesmente não desiste até fazer o outro rir. Quando seu amigo não aguenta de tanto rir, ele diz ao palhaço: Dude, you're just too funny.

[b] Steven Strong se encontra na fila de espera para ser atendido pelo médico, quando a secretária abre a porta do consultório e diz: Mister Strong? Steven Strong? 
Tendo em mente que tanto dude como mister são palavras usadas para se referir a pessoas, qual você acredita ser a diferença entre as duas situações?

Qual das duas situações acima você diria que é mais parecida com a do texto? Por quê? Em sua opinião, esse texto se aproxima mais da fala ou da escrita? Retire do texto elementos que reforcem sua resposta.

Você acha que a forma dos bonequinhos tem algum significado especial ou foi feito sem um propósito definido? Por quê?

O que acontece no desfecho da história?

Com relação ao significado da palavra dude, Roger traz uma atividade para contextualizá-la e trabalhar seu significado em oposição a mister, ambas usadas para dirigir-se a uma pessoa do sexo masculino. Roger problematiza o contexto de uso em que cada uma é utilizada. Na sequência, ele faz o aprendiz retornar ao texto para checar o uso da palavra, considerando a resposta da pergunta anterior. Essas perguntas trabalham seleção lexical contextualizada e distanciam-se de práticas como oferecer o significado da palavra ao aluno através de glossário ou lista de vocabulário. Ela também é mais complexa do que uma atividade na qual o aprendiz deve marcar a opção correta.

A próxima pergunta é: "Em sua opinião, esse texto se aproxima mais da fala ou da escrita? Retire do texto elementos que reforcem sua resposta." Conquanto peça a opinião do aprendiz, a pergunta faz com que ele tenha que buscar elementos no texto para dar suporte a ela. Faz com que o aluno analise a transposição do texto oral para uma situação de escrita, observando possíveis marcas que auxiliem a caracterizá-lo uma vez que a interação oral representada no texto é importante para que se entenda a crítica do autor.

Em seguida, ao perguntar "Você acha que a forma dos bonequinhos tem algum significado especial ou foi feito sem um propósito definido? Por quê?' Roger aborda diretamente mais uma questão semiótica e sua relevância para a construção de significados pelo leitor na interação com o autor através do texto. Finalmente, na última pergunta da leitura, o aprendiz já deve colocar o que entendeu sobre o desfecho da história. 
Todas as atividades e o seu encadeamento em uma unidade de leitura devem estar a serviço da compreensão do texto. Da mesma forma, aquelas em que o foco recai nos elementos sistêmicos. Considerando o texto selecionado por Roger e a reflexão que pretendia provocar, ele poderia ter abordado outras questões em outras atividades antes de solicitar ao aprendiz que oferecesse um entendimento sobre o desfecho da interação entre os personagens. Por exemplo, no que diz respeito aos elementos sistêmicos que compõem o texto, poderia ter produzido uma atividade para focalizar os verbos que apontam para ações no passado ligadas [a] ao personagem que interpela o outro pela falta de notícias mostrando sua ação no sentido de verificar indícios de atividade do interpelado no mundo social (checked); [b] ao personagem interpelado mostrando como não havia indícios de suas ações no mundo virtual (you disappeared, the last time you uploaded). Outro elemento a ser considerado seria o uso de advérbio de negação para enfatizar a falta de ações no mundo virtual ( $\underline{\text { no }}$ status updates, your blog hadn't been touched; there's no twitter activity).

Além disso, no tocante ao aspecto semiótico, talvez a pergunta em que Roger questiona se a maneira como os bonecos foram desenhados teria algum significado especial pudesse direcionar o olhar do aprendiz aos traços usados para desenhar o posicionamento dos braços. Embora novamente esteja alinhado à perspectiva dos multiletramentos, Roger poderia também focar os dois quadrinhos em que nada é dito, mas muito colaboram para a construção de significado. Finalmente, como não focalizou o título dos quadrinhos na pré-leitura, poderia voltar a ele após a atividade 4 para comparar uma primeira leitura que poderia ter sido feita sobre ele e, após as reflexões geradas pelas atividades, se a mesma leitura permaneceria.

Allwright e Hanks (2009), ao incorporarem ao rationale da Prática Exploratória algumas proposições sobre os alunos, defendem que eles "são capazes de tomar decisões de maneira independente". Assim, embora em muitos momentos da produção dessa unidade por Roger, eu houvesse sugerido modificações (algumas incorporadas e outras não), alinhei-me àquela asserção de Allwright e Hanks no sentido de entender que o encaminhamento dado à abordagem ao texto representava um momento da 
experiência formativa do bolsista. Ele havia tomado decisões fundamentadas em saberes que deveriam ser respeitados. Quando fosse implementá-la, poderia rever suas decisões e modificar as atividades da unidade ou não.

4.1.4 As atividades propostas aos alunos - III

Pós-leitura
Como você classificaria a amizade das duas personagens da história? Comente a
respeito do assunto.
O verbo follow em inglês significa seguir. Pensando não somente no universo virtual,
mas também no mundo físico, o que você acha dessa nova mania de seguir
(virtualmente) as pessoas?
Você acredita nessas novas redes sociais (Facebook, Orkut, Myspace, Twitter,
Instagran), como meios de aproximação de pessoas? Explique.

A pós-leitura é dedicada a fazer um movimento no sentido de ligar a temática do texto ao cotidiano do aprendiz no tocante às redes sociais. É um momento para discutir as promessas que aparecem na página inicial de redes sociais como Facebook (No Facebook você pode se conectar e compartilhar o que quiser com quem é importante em sua vida.), no Twitter (Conecte-se com seus amigos - e outras pessoas fascinantes.), no Flickr (Inspiring photography. Introducing the all new Flickr app. Share and connect with the Flickr Community.). Amizade e aproximação entre as pessoas são problematizadas e os alunos envolvidos na reflexão. Assim, toda a unidade de leitura produzida por Roger constituiu-se em uma APPE. Ela encorajava o aprendiz a pensar sobre um espectro da qualidade da vida do ser humano 'envolvido por' e 'usuário de' redes sociais. É relevante informar que Roger teve a oportunidade de implementar essa atividade em uma oficina que foi oferecida, através da extensão universitária, à comunidade do entorno.

\subsubsection{A Perspectiva de Roger - fragmentos de um relatório}

Como apontado na seção em que apresentei o projeto, os relatórios de atuação dos bolsistas eram também espaços discursivos de reflexão. Assim, além de descrever as atividades desenvolvidas, avaliar a atuação do 
orientador, indicar problemas para o desenvolvimento das atividades do projeto e fazer sugestões, elementos que faziam parte do modelo da institucional, os bolsistas do projeto utilizavam-no como ferramenta para reflexão. Abaixo há alguns fragmentos de um desses relatórios produzido por Roger.

[A]
Ao entrar no projeto [...] confesso que não sabia ao certo o que esperar. Durante o
meu percurso de graduação "pré-projeto", já não era incomum falarmos de um
ensino de língua inglesa que não privilegie somente o caráter sistêmico da língua,
isto é, elementos sintáticos, léxicos, morfológicos, fonêmicos, etc. estudados fora de
um contexto de uso real da língua. No entanto, não parecia haver na faculdade,
infelizmente, um momento em que efetivamente se transplantasse essa teoria em
prática. Em outras palavras, a eterna pergunta persistia: Como trazer tais
conhecimentos - tais visões de língua, de aluno, de professor - para a nossa prática
enquanto professores?
O projeto representa para mim justamente esse contexto em que não somente se
pensa, mas que se faz essa convergência entre teoria e prática. É aqui que
pensamos em atividades que criem um contexto de interação entre professor/aluno
e aluno/aluno - ou, porque não dizer, entre interactantes do contexto social sala de
aula - que possibilite a construção de sentido e, portanto, conhecimento na sala de
aula.

Já fazia parte de seu entendimento ao iniciar suas atividades no projeto que o ensino de língua não deve privilegiar o nível sistêmico apenas. Da mesma forma, um entendimento diferenciado sobre papéis de professor e de alunos nessa prática a ser instaurada. Em relação à produção do material didático, Roger menciona a preocupação no sentido de que contribua para a configuração de um espaço interacional e de construção de conhecimentos a partir de uma visão particular de língua e de aprendizagem ${ }^{4}$. No entanto, problematiza a falta de vivência dessas questões nas disciplinas que estudara até então: o distanciamento teoria-prática. É no projeto que ver concretizar tal oportunidade.

[B]
Eu, por exemplo, já não temo mais hoje situações em que seja necessário adotar o
meu papel social de professor. [...] sinto-me confiante de que sou capaz de ajudar a
construir um contexto em sala de aula que nos ajudará a entender um pouco melhor
de que modo e para que fins a língua é usada.

\footnotetext{
${ }^{4}$ A menção a "professor/aluno e aluno/aluno" é um indicativo de um entendimento do aprender pelo viés sociointeracional, conforme defendido pelos proponentes dos PCN-LE (BRASIL, 1998). O mesmo se aplica quando menciona 'construção de conhecimento em sala de aula'.
} 
Analisando a experiência vivida expressa no relatório, ressalto como Roger vê seu lugar no contexto profissional de atuação, ao falar em 'papel social de professor'. Era uma posição temida, mas a experiência permitiu que desenvolvesse alguma segurança não em um sentido estático, se posso colocar dessa forma. Roger sabe que tudo o que acontece na sala é negociado e coconstruído, por isso, ele pode ‘ajudar a construir um contexto' que permitirá a ele e aos aprendizes entender modos e finalidades de uso da língua. Considerando a atividade de leitura apresentada anteriormente é possível afirmar que conseguiu ir além de uma forma engessada de entender e ensinar a língua inglesa.

[C]

Dessa forma, posso afirmar sem dúvidas que, hoje, não mais acredito ser possível ver e lidar com a língua como se esta existisse num vácuo social; tanto é que hoje acredito que o papel mais fundamental do professor é o de tentar entender, juntamente com os alunos, de que modo os elementos da língua tradicionalmente estudados em isolado são utilizados para se alcançar o efeito desejado, seja em qual contexto enunciativo for. E é nesse processo de "reflexão conjunta" - e, consequentemente, interação - que é construído conhecimento. É nesse processo que crescemos enquanto seres socialmente críticos.

Ressalto, desse fragmento, o uso da expressão 'vácuo social' incorporada ao seu discurso a partir da fundamentação teórica que havíamos discutido nas reuniões de orientação. Mais do que incorporar ao discurso, fazia parte de seu entendimento sobre língua como discurso e sobre os discursos que circulam no mundo social.

Conforme mencionei, a Prática Exploratória e seus princípios orientavam as práticas que desenvolvíamos no projeto e, no relatório de Roger, marcas do fazer exploratório podem ser identificadas no discurso, como em:

[a] "o papel mais fundamental do professor é o de tentar entender, juntamente com os alunos, de que modo os elementos da língua tradicionalmente estudados em isolado são utilizados para se alcançar o efeito desejado, seja em qual contexto enunciativo for." - aqui se reflete a proposta da PE no sentido de envolver todos no processo de construção de entendimentos sobre questões relevantes para os praticantes. Nesse caso, juntos, professor e alunos podem agir para entender a língua sob outra 
perspectiva, mais alinhada à atual sócio-história, desconstruindo, portanto, uma visão fragmentada e estrutural da língua e substituindo-a por uma visão vinculada à ação, à construção de sentidos e de ideologias.

[b] “nesse processo de 'reflexão conjunta' que é construído conhecimento. É nesse processo que crescemos enquanto seres socialmente críticos." - a menção à reflexão conjunta reforça como a visão de sala de aula que Roger traz é fundamentada no olhar exploratório e do fazer reflexivo coletivo em que todos são agentes na construção de seus conhecimentos locais, mas, possivelmente relevantes para outras pessoas que se envolvam com questões da mesma natureza. Tal reflexão leva ao desenvolvimento, ou 'crescimento' nos termos de Roger, dos envolvidos. Cabe enfatizar que o novo entendimento sobre a língua, bem como a construção de um fazer docente alinhado à abordagem dos multiletramenteos têm o potencial fazer do licenciando e de seus alunos 'seres socialmente críticos', com um olhar diferenciado sobre a sócio-história atual.

\section{Ponto de chegada}

A análise da produção de Roger - seja a unidade de leitura, seja os fragmentos de seu diário - além de trazer à memória a imagem desse querido bolsista, em especial me faz repensar na responsabilidade dos formadores. $O$ percurso reflexivo delineado neste estudo, desde a discussão sobre a centralidade do discurso na vida que se vive na contemporaneidade até aqui, leva-me a entender que, face aos desafios, há muito ainda a refletir, a pesquisar e a fazer na área de formação do professor de inglês. Esse 'que fazer' é muito relevante no âmbito do ensinar novos professores pois, como afirma Freire (2011) "ensinar é um ato criador, um ato crítico e não mecânico. A curiosidade do(a) professor(a) e dos alunos em ação se encontra na base do ensinar-aprender". Isto leva o professor de inglês, em especial, para além do método, empoderando tanto um quanto o outro ao refletirem sobre suas práticas localizadas em salas de aula na sócio-história que vivemos, incluindo o pensar sobre novos designs para o mundo social. 


\section{Referências bibliográficas}

ABRAHÃO, M. H. V. Teoria e prática na formação pré-serviço do professor de língua. In: GIMENEZ, T. (org.) Trajetórias na formação de professores de línguas. Londrina: EDUEL, 2002.

ALLWRIGHT, D. Bringing work 'to life': Exploratory Practice for the language classroom. Lancaster University, 2001a. Disponível em:

www.ling.lancs.ac.uk/groups/crile/EPCentre/newsletter2002/html/principles of

$\underline{\mathrm{ep}}$

Acesso: Junho/2004.

ALLWRIGHT, D. Basic principles for Exploratory Practice. Lancaster University, Handout, 2001b. Disponível em:

http://www.letras.puc-rio.br/unidades\&nucleos/epcentre/background.htm

Acesso: Junho/2004.

ALLWRIGHT, D.; HANKS, J. The Developing Language Learner: An Introduction to Exploratory Practice. Hampshire: Palgrave Macmillan, 2009.

BAUMAN, Z. Globalização: as consequências humanas. Rio de Janeiro: Jorge Zahar Editores, 1999.

. Tempos Líquidos. Rio de Janeiro: Jorge Zahar Editores, 2007.

BRASIL, Parâmetros Curriculares Nacionais: Terceiro e quarto ciclos do ensino fundamental: Língua Estrangeira. Brasília: MEC: SEF, 1998.

COPE, B.; KALANTZIS; M. Multiliteracies: the beginnings of an idea. In: COPE, B.; KALANTZIS; M. (ed.) Multiliteracies - Literacy and the Design of Social Futures. London: Routledge, 2000.

CRISTOVÃO, V. L. L. Uma experiência de reflexão e formação de professores. In: GIMENEZ, T. (org.) Trajetórias na formação de professores de línguas. Londrina: EDUEL, 2002.

FAIRCLOUGH, N. Critical discourse analysis: the critical study of language. London: Longman, 1995.

. Language and Power. London: Longman, 1996.

FREIRE, P. Pedagogia da Esperança: um reencontro com a pedagogia do oprimido. São Paulo: Paz e Terra, 2011.

GIDDENS, A. Mundo em descontrole - o que a globalização está fazendo de nós. Rio de Janeiro: Record, 2003. 
GIEVE, S.; MILLER, I. K. de. What do we mean by 'Quality of Classroom Life'? In: GIEVE, S.; MILLER, I. K. de. (ed.) Understanding the language classroom. Hampshire: Pallgrave MacMillan, 2006.

GIROUX, H. A. Os professores como intelectuais: rumo a uma abordagem crítica da aprendizagem. Porto Alegre: Artmed, 1997.

GIROUX, H.; SIMON, R. Cultura popular e Pedagogia Crítica: a vida cotidiana como base para o conhecimento curricular. In: MOREIRA, A. F.; SILVA, T. T. (org.) Currículo, cultura e sociedade. São Paulo: Cortez Editora, 1994.

GOFFMAN, E. Frame analysis: an essay on the organization of experience. Harmondsworth: Penguin, 1974.

GOODWIN, C.; DURANTI, A. (Eds.) Rethinking Context. Cambridge: Cambridge University Press, [1992]1997.

JORDÃO, C.; FOGAÇA, F. C. Ensino de inglês, letramento crítico e cidadania: um triângulo amoroso bem-sucedido. In: Línguas e Letras, vol. 8, no 14, 1응 sem. 2007.

Disponível em:

e-revista.unioeste.br/index.php/linguaseletras/article/download/906/770

Acesso em: Maio/2010.

LIBERALI, F. C.; MAGALHÃES, M. C.C.; ROMERO, T. R. de S. Autobiografia, diário e sessão reflexiva: atividades na formação crítico-reflexiva de professores. In: BARBARA, L.; RAMOS, R. de C. G. (org.) Reflexões e ações no ensino-aprendizagem de línguas. Campinas: Mercado de Letras, 2003.

MATOS, J. C. Professor reflexivo? Apontamentos para o debate. In: GERALDI, C. M. G.; FIORENTINI, D.; PEREIRA, E. M. de A. (org.) Cartografias do trabalho docente: professor(a) pesquisador(a). Campinas: Mercado de Letras: Associação de Leitura do Brasil, 1998.

MILLER, I. K. de. Formação do professor de línguas: da eficiência à reflexão crítica e ética. In MOITA LOPES, L. P. (org.) Linguística Aplicada na Modernidade Recente. São Paulo: Parábola, 2013.

A Prática Exploratória na educação continuada de professores de línguas: inserções acadêmicas e teorizações híbridas. In: SILVA, K. A. da; DANIEL, F. de G.; KANEKO-MARQUES, S. M. (org.) A formação de Professores de Línguas: Novos Olhares - Volume I. Campinas: Pontes Editores, 2011.

MOITA LOPES, L. P. da. (Org.) Por uma Linguística Aplicada Indisciplinar. São Paulo: Parábola Editorial, 2006. 
MORAES BEZERRA, I.C.R. Prática Exploratória: a construção do ensino reflexivo, da formação docente e da pesquisa em contextos educacionais. (título provisório do livro em andamento)

- Prática exploratória, espaços formativos e a educação crítica de professores de inglês: o olhar híbrido de uma professora formadora. In: Revista X. UFPR, vol. 2, 2011.

Disponível em: http://ojs.c3sl.ufpr.br/ojs/index.php/revistax/article/view/23015 Acesso: fev/2012.

PESSOA, R. Formação crítica de professores de línguas estrangeiras. In: SILVA, K.A. da; DANIEL, F. de G.; KANEKO-MARQUES, S. M. (org.) A formação de Professores de Línguas: Novos Olhares - Volume I. Campinas: Pontes Editores, 2011.

RODRIGUES, R.L.A. A Prática Exploratória na formação de professores de Língua Inglesa: reflexão e ética no fazer pedagógico. Tese de Doutorado (Doutorado em Letras) - Rio de Janeiro: Departamento de Letras, Pontifícia Universidade Católica do Rio de Janeiro, 2014.

ROMERO, T. R. de S. Construindo a inclusão de futuros professores de inglês. In: SILVA, K.A. da; DANIEL, F. de G.; KANEKO-MARQUES, S. M. (org.) A formação de Professores de Línguas: Novos Olhares - Volume I. Campinas: Pontes Editores, 2011.

SANTOS, M. Por uma outra globalização: do pensamento único à consciência universal. Rio de Janeiro: Record, [2000]2011.

VILLELA, M. de M. Construindo entendimentos sobre a formação docente a partir de reuniões de orientação de estágio: um caminho exploratório. Tese de Doutorado (Doutorado em Letras) - Rio de Janeiro: Departamento de Letras, Pontifícia Universidade Católica do Rio de Janeiro, 2012.

WODAK, R. Critical discourse analysis and the study of doctor-patient interaction. In: GUNNARSSON, B.; LINELL, P. NORDBERG, B. The construction of professional discourse. London: Longman, 1997. 
Artigo recebido em: 15 de maio de 2014

Artigo aprovado em: 12 de setembro de 2014

\section{Sobre a autora:}

Isabel Cristina Rangel Moraes Bezerra é Doutora em Letras pela PUC-Rio. Atualmente é professora adjunta da Universidade do Estado do Rio de Janeiro, atuando no curso de Letras da Faculdade de Formação de Professores graduação (Português/Inglês), especialização (Pós em Educação Básica Ensino de Língua Inglesa) e mestrado (Mestrado Profissional em Letras). É membro do Grupo de Prática Exploratória do Rio de Janeiro e pesquisadora do grupo Linguagem e Sociedade (CNPq). Sua pesquisa envolve, principalmente, os seguintes temas: discurso institucional, ensino de língua estrangeira, construção de identidade, formação e reflexão docente, produção de material de ensino. 